\title{
Primary carcinoma of the gall bladder associated with ulcerative colitis
}

\author{
R. O’Connor, B. Harding, D. Greene and J. Coolican \\ Sir Patrick Dun's Hospital, Grand Canal Street, Dublin 2, Republic of Ireland.
}

\begin{abstract}
Summary: The report concerns a case of primary carcinoma of the gall bladder in a 53 year old man, who, 13 years previously underwent a pan-proctocolectomy for ulcerative colitis. Previous reports are reviewed, highlighting the difficulty of early diagnosis.
\end{abstract}

\section{Introduction}

Primary carcinoma of the gall bladder is a rare but recognized complication of ulcerative colitis (Ritchie et al., 1974). It is usually diagnosed late, when jaundice is well established. We report a case that presented as subacute small bowel obstruction.

\section{Case report}

A 53 year old man was referred to the outpatient department of the hospital in October 1985 with a 4month history of intermittent colicky peri-umbilical pain, associated with vomiting on two occasions. Thirteen years previously he had undergone a panproctocolectomy for fulminating ulcerative colitis, which failed to respond to intensive medical management. On examination he had a small incisional hernia, and as his history suggested intermittent small bowel obstruction, he underwent elective laparotomy to repair the hernia and release adhesions if present.

At operation the proximal small bowel was slightly distended. The site of obstruction was a loop of ileum in the right upper quadrant which was adherent to a carcinoma of the gall bladder. This had extended to involve the under surface of the liver. A cholecystectomy with wedge resection of liver and resection of involved ileum with end-to-end anastomosis was performed. Histology showed a moderately differentiated papillary carcinoma of the gall bladder. There were no gall stones present. The patient made an uneventful post-operative recovery.

It was noted pre-operatively that the patient's total bilirubin was marginally elevated at $21 \mu \mathrm{mol} / 1$ (normal $0-16)$ as was serum alkaline phosphatase of $107 \mathrm{IU} / 1$

Correspondence: B. Harding, F.R.C.S.I.

Accepted: 27 February 1986 (normal 30-100). These both returned to normal following surgery.

\section{Discussion}

The association of carcinoma of the extra-hepatic biliary system with ulcerative colitis is well documented. Ritchie and his associates (1974) reviewed 67 such cases. The incidence of this complication has been estimated as $0.4 \%$ (Ritchie et al., 1974) and $1.4 \%$ (Roberts-Thomas et al., 1973). It occurs 5 to 10 times more frequently than in an unselected patient population.

Primary carcinoma of the gall bladder has previously been noted on 11 occasions in patients with ulcerative colitis. No clinical details are available from five of these (Dawson \& Pryse-Davies, 1959; Downing \& Ferguson, 1964; Stauffer et al., 1966; Warren et al., 1968). The others are described in varying detail (Stauffer et al., 1965; Ham, 1968; Morowitz et al., 1971; Ritchie et al., 1974; Joffe \& Antonioli, 1981). Review of these reports (including the present case) shows that carcinoma of the gall bladder occurred in patients between the age of 44 and 59 years (median 54 years). This is 10 to 15 years earlier than the peak incidence in the general population (Piehler \& Crichlon, 1978). All had a long history of ulcerative colitis, ranging from 5 to 28 years (median 20 years). Two patients had undergone a pan-proctocolectomy over 10 years previously, and this does not appear to afford protection. Biliary calculi were not a feature of any of the cases. Diagnosis was achieved late in all; at laparotomy in five, by node biopsy in one, and at postmortem examination in the remaining case.

Liver function tests recorded in five cases show wide variation at presentation. Total bilirubin varied from 
normal in one patient to 12 times normal in another. Serum alkaline phosphatase was marginally elevated in our patient but was over three times normal in the others reported. A recent review (Christophi \& Hughes, 1985) suggests that because of the possible development of hepatobiliary disorders, patients with ulcerative colitis should have serum alkaline phosphatase estimation performed every 6 months, and those with persistent elevation, or more overt clinical

\section{References}

CHRISTOPHI, C. \& HUGHES, E.R. (1985). Hepatobiliary disorders in inflammatory bowel disease. Surgery, Gynecology \& Obstetrics, 160, 187.

DAWSON, I.M.P. \& PRYSE-DAVIES, J. (1959). The development of carcinoma of the large intestine in ulcerative colitis. British Journal of Surgery, 47, 113.

DOWNING, W.K. \& FERGUSON, J.A. (1964). Chronic ulcerative colitis. Experience with medical and surgical management of 292 patients. Diseases of the Colon and Rectum, 7, 278.

HAM, J.M. (1968). Tumours of the biliary epithelium and ulcerative colitis. Annals of Surgery, 168, 1088.

JOFFE, N. \& ANTONIOLI, D.A. (1981). Primary carcinoma of the gall bladder associated with chronic inflammatory bowel disease. Clinical Radiology, 32, 319.

MOROWITZ, D.A., GLAGON, S., DORDAL, E. \& KIRSNER, J.B. (1971). Carcinoma of the biliary tract complicating chronic ulcerative colitis. Cancer, 27, 356.

PIEHLER, J.M. \& CRICHLON, R.W. (1978). Primary carcinoma of the gall bladder. Surgery, Gynecology \& Obstetrics, 147929. manifestations of liver disease, need further investigation. However, despite a relatively normal alkaline phosphatase level, our patient had extensive carcinoma, highlighting the difficulty in early diagnosis of this complication. Indeed, had not a loop of ileum somewhat fortuitously become involved in the tumour mass, giving rise to symptoms, the diagnosis would have been even further delayed.

RITCHIE, J.K., ALLAN, R.N., MCCARTHY, J., THOMPSON, H., HAWLEY, P.R. \& COOKE, W.T. (1974). Biliary tract carcinoma associated with ulcerative colitis. Quarterly Journal of Medicine, 170, 263.

ROBERTS-THOMSON, I.C., STRICKLAND, R.G. \& MACKAY, I.K. (1973). Bile duct carcinoma in chronic ulcerative colitis. Australian and New Zealand Journal of Medicine, 3, 264.

STAUFFER, M.H., SAUER, W.G., DEARING, W.N. \& BAGGENSTOSS, A.H. (1965). The spectrum of cholestatic hepatic disease. Journal of the American Medical Association, $191,829$.

STAUFFER, M.H., SAUER, W.G., DEARING, W.H. \& BAGGENSTOSS, A.H. (1966). Biliary tract carcinoma: a complication of liver disease with ulcerative colitis. Gastroenterology, 50, 401.

WARREN, K.W., HARDY, K.J. \& O'ROURKE, M.G. (1968). Primary neoplasm of the gall bladder. Surgery, Gynecology \& Obstetrics, 126, 1036. 